\title{
Anomalous origin of left coronary artery from pulmonary artery associated with an aorto-pulmonary septal defect
}

\author{
P. Vassallo Agius, A. Rushworth, and N. Connolly \\ From the Department of Paediatrics, Brompton Hospital, London S.W.3
}

\begin{abstract}
Aorto-pulmonary septal defects and anomalous origins of left coronary artery from pulmonary artery are briefly discussed. The difficulties of diagnosis and surgical correction are put forward in a situation when the left coronary artery arises from a site of high pressure and saturation, such as the pulmonary artery in the presence of an aorto-pulmonary septal defect, as in the case described.
\end{abstract}

This report describes the clinical, haemodynamic, angiographic, and necropsy findings in an infant with anomalous origin of the left coronary artery from the pulmonary artery, small ventricular septal defect, aorto-pulmonary septal defect, right aortic arch, and left brachiocephalic trunk. We have been unable to find a report of a similar combination of defects, though the brief details are recorded of a haemodynamically comparable patient with aorto-pulmonary septal defect, right aortic arch, and anomalous origin of the right coronary from the pulmonary artery which was corrected successfully by surgery (Morrow, Greenfield, and Braunwald, 1962).

\section{Case report}

The patient, the only child of healthy parents, was a spontaneous normal hospital delivery at $\mathbf{4 2}$ weeks' gestation following an uneventful pregnancy, birthweight $3,200 \mathrm{~kg}$. There was no difficulty in onset of respiration. He was noted to be tachypnoeic from birth and fed poorly, though there was no other evidence of heart failure, and no heart murmur was heard. He was admitted to another hospital at the age of 2 months with probable cyanosis, a grade $3 / 6$ systolic murmur, and congestive heart failure. The latter responded slowly to medical treatment, and he was discharged two months later on no maintenance therapy. He failed to thrive, developed a persistent cough, and was referred to Brompton Hospital at the age of 6 months. On examination he was an ill infant with mild central cyanosis on crying. The length and weight were both below the third percentile. He had grunting respiration (rate 60/ min.), with conspicuous indrawing of both sides of the chest, right more than left, and suprasternal retraction. The peripheral pulses were 'waterhammer' in type, blood pressure $90 / 50 \mathrm{~mm}$. Hg. The heart was overactive and the second sound was single. There was a grade $3 / 6$ long ejection murmur best heard at the upper left sternal border and no diastolic murmur. The lungs were normal on auscultation. The liver edge was felt $2-3 \mathrm{~cm}$. below the right costal margin. No other abnormality was detected on routine clinical examination, except for a mild degree of hypospadias and shovel pinnae. Relevant investigations were: femoral arterial oxygen saturation 88 per cent; chest $x$-ray showed cardiomegaly with pulmonary plethora; electrocardiogram showed biventricular and biatrial hypertrophy with a mean frontal plan QRS axis of $+70^{\circ}$ with clockwise rotation.

Cardiac catheterization via the right axillary route was performed under local anaesthesia (see Table). The right ventricular pressure was at systemic level. There was a small left-to-right shunt at

TABLE Haemodynamic data

\begin{tabular}{|c|c|c|}
\hline Site & $\mathrm{O}_{2}$ sat. $\%$ & Pressure $(\mathrm{mm} . \mathrm{Hg})$ \\
\hline Superior vena cava & 59 & 一 \\
\hline $\begin{array}{l}\text { Inferior vena cava } \\
\text { Right atrium }\end{array}$ & $\begin{array}{l}69 \cdot 79 \\
60\end{array}$ & $\begin{array}{l}\bar{a}=6 \quad x=3 \\
\text { mean }=4\end{array}$ \\
\hline Low right ventricle & 63 & $80 / 10$ \\
\hline High right ventricle & 71 & $80 / 10$ \\
\hline Pulmonary artery & 90 & $75 / 45$ \\
\hline $\begin{array}{l}\text { Pulmonary artery } \\
\text { wedge }\end{array}$ & - & mean $=20$ \\
\hline Right axillary artery & 98 & $78 / 45$ \\
\hline
\end{tabular}


ventricular level and a large left-to-right shunt at pulmonary artery level. Selective angiogram, with an injection of $6 \mathrm{ml} .75 \%$ Triosil $^{1}$ into the right ventricle, showed an anteriorly placed pulmonary artery and 'washing-out' of contrast medium from the left pulmonary artery. The left coronary artery opacified from the pulmonary artery (Fig. I). The ventricular septal defect was not visualized. An aortogram showed opacification of both aorta and pulmonary artery, but it was not clear at what level the communication occurred. A right-sided aortic arch and a separate left brachiocephalic trunk were outlined. Aortography (Dr. G. A. H. Miller) was repeated a few days later and showed better definition of the aortopulmonary communication, midway between the usual site of a persistent ductus arteriosus and that of an aorto-pulmonary septal defect. A normal right coronary artery was well opacified, but no left coronary artery was seen.

A diagnosis was made of aorto-pulmonary communication with a large left-to-right shunt (? aorto-pulmonary septal defect, ?? persistent ductus arteriosus), anomalous left coronary artery arising from the pulmonary artery, right aortic arch, ? small ventricular septal defect, right descending aorta, and left brachiocephalic trunk.

He failed to improve with medical treatment and so a thoracotomy (Mr. M. Paneth) was performed and the pulmonary arteries banded, but he died a few hours after operation. The findings at the time of operation were interpreted as those of a truncus arteriosus.

Necropsy In place of the normal great vessels, an apparently single vessel, $I \mathrm{~cm}$. in diameter, arose from the base of the heart. Incision of this structure showed normally situated aortic and pulmonary valves separated by a septum. The vessel divided into a right aortic arch and a left brachio-

${ }^{1}$ Glaxo Laboratories, Greenford, Middlesex, England.

FIG. I Left coronary artery arising from pulmonary artery shown by a right ventricular injection.

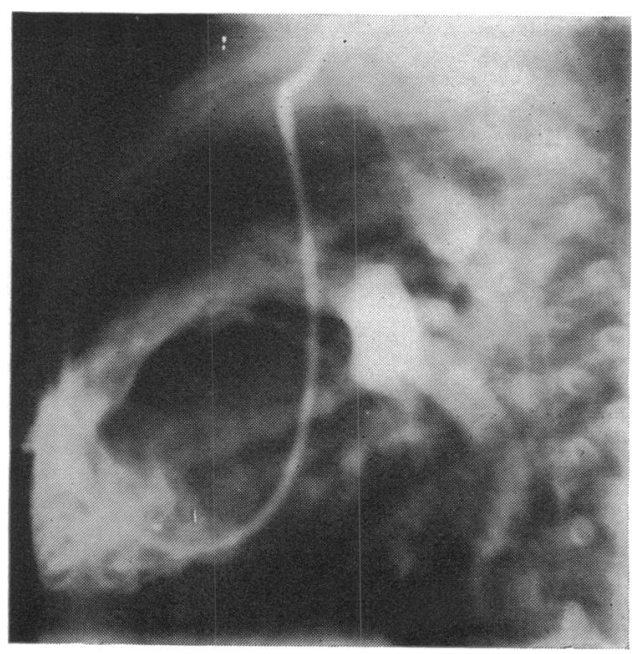

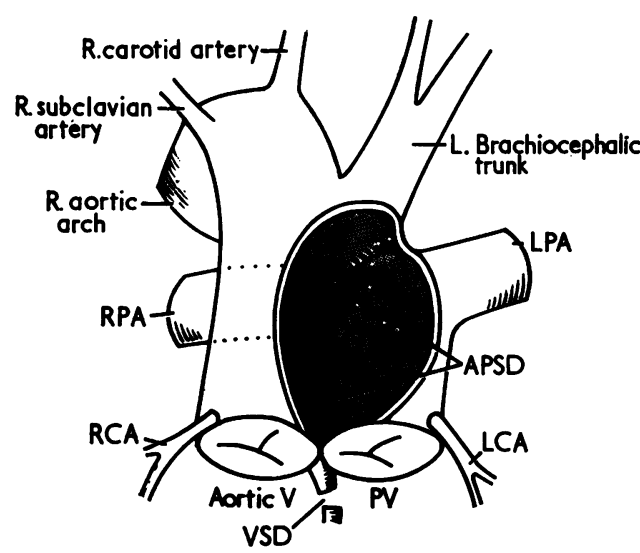

FIG. 2 Diagram to show position of large aorto-pulmonary septal defect, left brachiocephalic trunk, anomalous left coronary artery, and right aortic arch.

cephalic trunk on the side of the aortic valve, and into two main pulmonary arteries on the side of the pulmonary valve. A large aorto-pulmonary septal defect extended from the upper limit of the septum, $0.6 \mathrm{~cm}$. above the valves, to a ridge dividing the left brachiocephalic trunk and the main pulmonary artery (Fig. 2). The right coronary artery arose normally from the anterior sinus of Valsalva. The left coronary artery arose from the antero-lateral sinus above the pulmonary valves and divided almost immediately into the anterior descending and lateral branches to supply the myocardium normally supplied by the left coronary artery.

\section{Discussion}

A right aortic arch is often associated with supravalvular bulbo-septal malformation (D'Cruz et al., 1966). In this case the right aortic arch, pulmonary artery, and left brachiocephalic trunk intercommunicated by means of an aorto-pulmonary septal defect.

Aorto-pulmonary septal defect is a rare congenital anomaly of the great vessels. Abbott (1936) found ro cases in her review of 1,000 cases of congenital heart disease. Some 90 cases have now been reported. The defect arises from partial failure of the development and fusion of the longitudinal ridges which divide the primitive trunk.

Anomalous origin of the left coronary artery from the pulmonary artery is rare. First described at necropsy more than 75 years ago (Brooks, 1886), it remained a pathological curiosity until Bland, White, and Garland described in 1933 the classical electrocardiographic abnormalities of anomalous left coronary artery in an infant with congestive heart failure.

Interarterial coronary anastomoses have 
been shown in the normal newborn (Laurie and Woods, 1958). With the fall in pulmonary arterial pressure that normally occurs a few hours or days after birth and in the absence of a significant left-to-right shunt, the further development of these anastomoses in cases of anomalous origin of the left coronary artery from the pulmonary artery is crucial for survival. Under such circumstances reversal of flow occurs with development of a left-torights hunt (right coronary artery-anastomoses-left coronary artery to pulmonary artery). If because of other anomalies the pulmonary artery contains highly saturated blood at a high pressure the stimulus to the development of these anastomoses is not present. In this latter situation, as in our case, the classical ischaemic features in the electrocardiogram are not found, and correction of the defect will result in a reduction of the pulmonary artery pressure and a fall in oxygen saturation in the left coronary artery. Otherwise, the condition will often remain unrecognized until adult life, presenting as myocardial ischaemia or as an unsuspected finding at necropsy (George and Knowlan, 1959).

Retrograde aortography will usually show retrograde filling of left coronary artery into the pulmonary artery if pressure is normal; but filling of the left coronary artery can be shown by selective right ventricular angiography only if the pulmonary artery pressure, as in this case, approaches systemic level.

To our knowledge the association of aortopulmonary septal defect with the left coronary artery arising from the pulmonary artery has not been described, though a right coronary artery arising from the pulmonary artery (Morrow et al., 1962) and from a persistent ductus (Schumacher, 1957) have been described in association with an aorto-pulmonary septal defect which represents haemodynamically a similar situation.

Before the operation, it was appreciated that closure of the aorto-pulmonary communication was likely to involve left coronary transplantation. What was not appreciated from investigation or at thoracotomy was that the defect involved the left brachiocephalic trunk. The appearances at operation were those of a truncus, type II (Collett and Edwards, 1949), and as the clinical problem was intractable heart failure due to the large left-to-right shunt, banding of the separate right and left pulmonary arteries was performed. The extent and complexity of the anomaly could only be appreciated at necropsy.

We would like to thank Dr. B. Gans, Lewisham Hospital, for referring his case, Dr. G. A. H. Miller, Director of the Cardiac Laboratories, Brompton Hospital, for helpful advice and criticism, and Dr. M. C. Joseph, Brompton Hospital, for allowing us to publish this.

\section{References}

Abbott, M. E. (1936). Atlas of Congenital Cardiac Disease. American Heart Association, New York.

Bland, E. F., White, P. D., and Garland, J. (1933). Congenital anomalies of the coronary arteries. Report of an unusual case associated with cardiac hypertrophy. American Heart fournal, 8, 787.

Brooks, H. St. J. (1886). Two cases of an abnormal coronary artery of the heart arising from the pulmonary artery. Fournal of Anatomy and Physiology, 20, 26.

Collett, R. W., and Edwards, J. E. (1949). Persistent truncus arteriosus: a classification according to anatomic types. Surgical Clinics of North America, 29, 1245.

D'Cruz, I. A., Cantez, T., Namin, E. P., Licata, R., and Hastreiter, A. R. (I966). Right-sided aorta. Part II: Right aortic arch, right descending aorta, and associated anomalies. British Heart fournal, 28, 722 .

George, J. M., and Knowlan, D. M. (1959). Anomalous origin of the left coronary artery from the pulmonary artery in an adult. New England fournal of Medicine, 261, 993.

Laurie, W., and Woods, J. D. (1958). Anastomosis in the coronary circulation. Lancet, $2,812$.

Morrow, A. G., Greenfield, L. J., and Braunwald, E. (1962). Congenital aortopulmonary septal defect. Clinical and hemodynamic findings, surgical technic, and results of operative correction. Circulation, $25,463$.

Schumacher, H. B. (1957). In discussion of Cooley, D. A., McNamara, D. G., and Latson, J. R. Aorticopulmonary septal defect: diagnosis and surgical treatment. Surgery, 42, I20. 